\title{
Optimization of Engine Parameters using NSGA II for the Comprehensive Reduction of Emissions from VCR Engine Fuelled with ROME Biodiesel
}

\section{Murugapoopathi Saravanamuthu}

PSNA College of Engineering and Technology

Ramachandran Thulasiram ( $\square$ ramji.kkp@gmail.com )

Jain (Deemed-to-be University) https://orcid.org/0000-0002-6991-0403

Dharmalingam Ramasamy

Pragati Engineering College

Surendarnath Sundaramoorthy

Sri Venkateshwara College Engineering of Technology

\section{Research Article}

Keywords: ROME, Emissions, RSM, NSGA II

Posted Date: January 21st, 2022

DOI: https://doi.org/10.21203/rs.3.rs-1153209/v1

License: () (1) This work is licensed under a Creative Commons Attribution 4.0 International License.

Read Full License

Version of Record: A version of this preprint was published at Environmental Science and Pollution Research on April 4th, 2022. See the published version at https://doi.org/10.1007/s11356-022-19752-4. 


\section{Abstract}

Diesel engines are most widely used as power plant for many applications, like automotive, agricultural purposes, portable machines and remote location power generation, because of their higher torque, power output, energy content per unit mass and cost of fuel. Because of the higher compression ratios, the diesel engines are able to produce greater cylinder pressures resulting in higher temperatures and thermal efficiency. On other hand, the diesel engines produce $\mathrm{CO}_{x}, \mathrm{NO}_{x}$, Soot and sulphur emissions which are harmful and pollute the environment leads to acid rain, global warming and variety of human diseases. Also, the Present emission regulations are framed such a way to ensure the environmental sustainability in addition to the economic and social importance. These constraints make the researchers to find an alternate fuel for replacing the diesel fuel on the existing diesel engines for the reduction of environmental pollutions. Biodiesel is found to be a very good alternative fuel obtained from natural resources and having good energy with least possible emissions. Rubber seed methyl ester (ROME) is one kind of the biofuel can be used in the existing diesel without any engine modifications. The ROME is produced using trans esterification process and the biodiesel blends are prepared in the sequence of B20, B40, B60 and B80. The ROME is tested on the Variable Compression Ratio (VCR) engine to test the emission characteristic in line with the performance characteristics. To reduce the emissions, the prediction models are developed for $\mathrm{CO}$ and $\mathrm{NO}_{\mathrm{x}}$ using the Response Surface Methodology (RSM). The models are verified through the ANOVA and p-test for their adequacy to create the hypothesis of the experimentation. The NSGA II evolutionary multi-objective optimization is used to optimize the engine parameters to minimise the pollutions from the ROME fuelled engine. Finally, the optimized parameters are verified though the experimentation to verify the least possible emissions from the engine.

\section{Introduction}

The inventors were keen to concentrate on vegetable oils as alternatives due to the daily rising costs of imported hydrocarbons and their growing particulate emissions in the ecosystem. The majority of study found that the qualities of plant oils in diesel engines were nearly identical to those of diesel (Bielaczyc, P., \& Woodburn, J. 2019). Vegetable oil is used in diesel engines because of its increased viscosity and higher carbon residue. Transesterification of vegetable oil improves engine efficiency by lowering oil viscosity and carbon content in diesel engines. By reducing the molecular dimensions of vegetable oil, the physical qualities of the oil are improved. Without any significant changes, transesterification decreases the viscosity and makes it appropriate for diesel. Biodiesel contains no sulphur and contains oxygen in its particles, which improves the combustion characteristics when compared to fossil fuels (Hoang, A. T. et al 2021). Variable compression ratio is a technology that enables a diesel engine's compression ratio to be varied to improve fuel savings under varying load situations. Due to increases in dynamic characteristics, oil prices, and power requirements in commercial applications, it permits the top dead centre above the piston to adjust the volumes. The engine's thermal efficiency was improved by increasing the pressure inside the cylinder at higher compression (Aghbashlo et al 2021). In an internal combustion engine, a higher penetration pressure produced higher power and torque. At high speed and full load on the engine, 
the combustion interval of an engine was restricted. To produce maximum power output, more fuel must be supplied within this time frame, and high pressure causes the engine more effective. High injection pressure can be used to reduce emissions in engines. ANN and RSM modelling techniques were utilised to find the best blending proportion in a $\mathrm{Cl}$ engine using an animal waste fat biofuel. The best blending was found to be $22 \%$, and the results of the study were in good agreement with the prediction model with minimal error (Simsek et al 2021). A comparison of engine analysis using RSM and ANN with 17.88 percent blended fuel, 35 advanced CA, and 780 watt engine load to test palm oil biofuel. Then use a statistical method with realistic engine output data, the best outputs for $\mathrm{CO}, \mathrm{HC}, \mathrm{NOx}$, and smoke were recorded. (Uslu 2020). Using a multi-objective fuzzy based GA approach, the engine performance (BTE, BSFC) and emission (CO, NOx) output values were optimised. For Thumba biodiesel of $10 \%$ with $10 \%$ butanol blends IDI Cl engine, the best results produced using GA show a strong correlation with experimental data. $\mathrm{CO}$ and UHC emissions were reduced as BTE was increased with a $5.1 \mathrm{~kg}$ optimal load for the abovementioned blend. (Debnath et al 2019). Soyabean biodiesel $(10 \%, 20 \% \& 30 \%)$ blended water $(10 \%, 20 \% \& 30 \%)$ with Al Nano particle $(50,100$ \& 150 ppm) experimentally investigated in single cylinder diesel engine. Experimentally explored in single cylinder diesel engine using soyabean biodiesel $(10 \%$, $20 \%$, and $30 \%$ ) blended water $(10 \%, 20 \%$, and $30 \%$ ) with Al Nano particle $(50,100$, and $150 \mathrm{ppm})$. Grey rational analysis was used to optimise the operating parameters based on the observations (CO, HC, BSEC and SFC, smoke). With a combination of $20 \%$ blend, $10 \%$ water, and $100 \mathrm{ppm}$ Nano particle, the best performance and greenest emissions were achieved (Vellaiyan et al 2019). The optimum engine operating conditions of diesel engine was achieved using RSM tool with fusel oil of alcohol based by-product $(5,10,15,20 \%)$ mixed with biodiesel $(5,10,15,20 \%)$ with diesel for different operating conditions as load $(0,25,50,78$ and $100 \%)$, speed $(1400,1700,2000,2300 \& 2600 \mathrm{rpm})$. The optimum reduction in $\mathrm{CO}, \mathrm{HC}$ and $\mathrm{NO}_{\mathrm{x}}$ emissions were observed for $5 \%$ fusel oil with $5 \%$ biodiesel and $90 \%$ blending, $2026 \mathrm{rpm}$ and $46 \%$ using RSM prediction method (Pour A H et. al. 2018). Experiments were carried to optimize the emission responses (CO \& HC) of VCR engine using RSM and ANN. The adequacy of the model was tested using ANOVA table and results were used for ANN prediction models. The optimized models were tested experimentally to reduce the emissions on VCR engine (Tulsiram et al 2021).

Most of the research works were proved that the lower blends of biodiesel feedstocks exhibited tail lower pipe emissions with improved the performance in $\mathrm{Cl}$ engine without any engine modification. As the engine performance and emissions characters are significantly influenced by the factors like compression ratio (CR), fuel injection pressure (FIP), supercharging (SC) and load they were considered as variables in this research work. But the determination of optimistic operating conditions for least emissions for an engine running with biodiesel is a challenging task. To resolve this difficulty and to create a hypothesis for the experiment, the statistical technique (RSM) is used to develop the experimental design matrix and the experiments were conducted considering the BTE, SFC, $\mathrm{CO}, \mathrm{HC}$ and NOx as responses. The experimental results were simulated through the RSM and experimental correlations were obtained for the responses. The variables considered here are optimised using the multi objective evolutionary optimization technique (NSGA II) to minimise the emissions from the engine. Finally, the optimised to results are verified through 
the test engine to validate them. The results are also compared with neat diesel and other operating conditions to justify the impact of emissions on the environmental pollution.

In this research work, performance and emission characterisation of the ROME was carried out in with the aim of minimizing the $\mathrm{CO}$ and $\mathrm{NO}_{\mathrm{x}}$ with maximum possible performance of the engine. The most feasible operating condition of $\mathrm{Cl}$ engine is a challenging task with experimental methodology. The process involved in various engine operating parameters with variety of fuel blends makes it tedious one.

\section{Materials And Methods}

\subsection{Extraction of Rubber seed oil}

Commercialization of biodiesel as IC engine fuel has a number of issues related to production, conversion and distribution and these issues must be addressed in order to make economically viable fuel. Nonedible oils like Jatropha, Pongamia, animal fat, waste cooking oil, and rubber seed oil are suggested to be used as alternate fuels in existing diesel engines to minimise the production and operational costs with reduced emissions. Rubber seed oil is a kind of non-edible oil that cannot be used for cooking and house hold applications (Murugapoopathi \& Vasudevan 2019a). The major countries around the world that grow rubber trees for the production of the rubber and by products are Brazil, Nigeria, Sri Lanka, Malaysia, India, Thailand, Indonesia, Vietnam, and Cambodia. Generally, rubber is grown in the central highlands of Kerala, Karnataka, and Tamil Nadu states, as well as the steep hills of north east India (Onoji et al 2016). In some of the coastal regions in Goa, Andhra Pradesh, Orissa, and Maharashtra rubber trees are grown for their resin. Roughly 85 percent of rubber trees are grown in Tamil Nadu's, Kerala, and Karnataka, that covers 7.35lakh hectares, with an annual output of 9.1 lakh metric tonnes (Murugapoopathi \& Vasudevan 2021a). From the rubber trees, Rubber seed collection per hectare is $150 \mathrm{~kg}$ per year, with each tree producing $500 \mathrm{~g}$ of seeds. Rubber tree residue has three, elliptical shells that are $2-3 \mathrm{~cm}$ long and weigh $3-4 \mathrm{~g}$ from which the seeds are removed and processed. For the processing, the seeds are harvested, and the kernels are separated from the shells by shattering. The rubber seed has approximately $50-60 \%$ shell with $20-25 \%$ moisture, and the dried kernel contains $40-50 \%$ oil in it. The oil is extracted by crushing and filtering the dried nuts. Rubber seed oil is now being used in a wider range of biodiesel production processes (Murugapoopathi et.al 2019b). In this research experimentation, rubber seed is used as a feed stock for the manufacturing of biofuel to replace the diesel fuel.

\subsection{Production of biodiesel}

To extract the rubber seed oil, the rubber seeds are dried, squeezed, and centrifuged. The crude Rubber Seed Oil (RSO) is extracted and deposited in the collection tube then the soap stock is pressed. Rubber seed oil has a high free fatty acid content of 12.21 percent (Murugapoopathi et al 2019c). Rubber seed oil contains more than $2 \%$ FFA, and the direct alkaline esterification procedure lowers the ester formation yield. Because of the higher viscosity of rubber seed oil, an acid and alkaline esterification procedure is performed to maximize production. Through the alkaline esterification process, the acid value is greatly lowered in order to increase the methyl esters of rubber seed oil. Reaction temperature, molar ratio of 
alcohol and oil, catalyst, reaction time, and the existence of FFA concentration are all elements that influence the synthesis of methyl esters from vegetable oils. Maximum production of methyl ester yields are obtained when the reaction temperature is between 45 and $70^{\circ} \mathrm{C}$ at atmospheric pressure. The amount of biodiesel produced is mostly determined by the type of esterification used. The molar ratio of alcohol utilised during the esterification process is critical in the synthesis of methyl esters. During the esterification process, most studies found that a molar ratio of 5:1 gives the highest production of biodiesel. The type of catalyst utilised in the biodiesel synthesis improves the reaction. The acid esterification method reduces the FFA level of the rubber seed oil to less than $2 \%$, and it is the initial stage in using sulphuric acid as a catalyst. To begin, make $3.5 \mathrm{~mL}$ sulphuric acid and dilute it with $200 \mathrm{ml}$ methanol before adding it to the warmed oil. A magnetic stirrer is used to continually swirl the mixture for around thirty minutes. The mixture is then allowed to settle in a separate measuring jar, where the contaminants and surplus alcohol are collected at the top. First, make the methoxide by mixing $4 \mathrm{~g}$ of potassium hydroxide with $300 \mathrm{ml}$ of methanol as a catalyst. To make potassium meth oxide, the magnetic stirrer is utilised to dissolve the potassium hydroxide in the methanol. In a separate container, one litre of oil is mixed with the meth oxide at a steady temperature. To separate the methyl esters from the glycerine, the mixture is agitated for 20-30 minutes. In the presence of potassium hydroxide, the triglyceride and the methanol react to generate monoesters and glycerine. The mixture is allowed to settle for 6-8 hours. One litre of distilled water is added to the mixture, which is then allowed to settle. The biodiesel-containing top floating layer is eliminated. Finally, the biodiesel is heated to $90-110^{\circ} \mathrm{C}$ to eliminate the remaining water. The maximum yield of $952 \mathrm{~mL}$ of Rubber seed Oil Methyl Esters (ROME) is obtained through two step transesterification process from one litre of RSO. The produced ROME is mixed with diesel at various proportions at 20,40,60 and 80percent on volume basis and are tested in laboratory as per ASTM standards. The density, viscosity, flash point, fire point, and gross calorific value of biodiesel are all measured and compared to that of pure diesel (Table.1). After transesterification, the viscosity of pure rubber seed oil methyl esters is greatly reduced. Biodiesel's flash and fire points are comparable to those of diesel. Biodiesel has a heating value of 81.83 percent, which is comparable with diesel.

Table: 1 Properties of biodiesel and diesel as per the Measurements standard 


\begin{tabular}{|c|c|c|c|c|c|c|c|c|}
\hline \multirow[t]{2}{*}{ Properties } & \multirow[t]{2}{*}{ Diesel } & \multirow[t]{2}{*}{ B20 } & \multirow[t]{2}{*}{ B40 } & \multirow[t]{2}{*}{ B60 } & \multirow[t]{2}{*}{ B80 } & \multirow[t]{2}{*}{ B100 } & \multicolumn{2}{|c|}{$\begin{array}{l}\text { Biodiesel } \\
\text { standards }{ }^{a, b}\end{array}$} \\
\hline & & & & & & & $\begin{array}{l}\text { ASTM } \\
\text { D6751- } \\
02\end{array}$ & $\begin{array}{l}\text { IS } \\
1448 / \\
\text { DIN } \\
\text { EN } \\
14214\end{array}$ \\
\hline Density $\left(\mathrm{Kgm}^{-3}\right)$ & 0.835 & 0.82 & 0.86 & 0.87 & 0.88 & 0.89 & - & $\begin{array}{l}0.86- \\
0.90\end{array}$ \\
\hline $\begin{array}{l}\text { Viscosity at } \\
40^{0} \mathrm{C}\left(\mathrm{mm}^{2} \mathrm{~s}^{-1}\right)\end{array}$ & 1.382 & 1.032 & 1.212 & 1.45 & 2.24 & 3.42 & $1.9-6.0$ & $\begin{array}{l}3.5- \\
5.0\end{array}$ \\
\hline Flash Point & $42^{0} \mathrm{C}$ & $50^{\circ} \mathrm{C}$ & $56^{\circ} \mathrm{C}$ & $65^{\circ} \mathrm{C}$ & $120^{\circ} \mathrm{C}$ & $210^{\circ} \mathrm{C}$ & $>130$ & $>120$ \\
\hline Fire Point & $65^{0} \mathrm{C}$ & $54^{0} \mathrm{C}$ & $60^{\circ} \mathrm{C}$ & $75^{\circ} \mathrm{C}$ & $160^{\circ} \mathrm{C}$ & $230^{\circ} \mathrm{C}$ & - & - \\
\hline $\begin{array}{l}\text { Calculated Cetane } \\
\text { Index }\end{array}$ & $45-55^{c}$ & 49 & 47 & 45 & 41 & 39 & $41 \mathrm{~min}$ & $\begin{array}{l}51 \\
\min \end{array}$ \\
\hline $\begin{array}{l}\text { Gross Calorific Value } \\
\left(\mathrm{KJ} \mathrm{Kg}^{-1}\right)\end{array}$ & $45200^{c}$ & 41343 & 40200 & 39129 & 38070 & 36986 & - & - \\
\hline
\end{tabular}

a,b Murugapoopathi \& Vasudevan (2021a) ～cMurugapoopathi et al (2021b)

\subsection{Experimental procedure}

The biodiesel blends prepared are to be tested for the performance and emission characteristics for that the test engine used is of a single-cylinder four-stroke cycle Variable Compression Ratio (VCR) Engine. The test engine is of electronic fuel injection type coupled with eddy current dynamometer to measure the power output of the engine. The test engine setup (Fig.1) is equipped with the computer assisted data acquisition system such that the engine test parameters are collected and stored in the computer software during each cycle of experimentation. The variation of the brake load on the eddy current dynamometer, fuel supplied to the engine (through solenoid valve) are controlled through software system. The pressure transducer placed on the fuel injector is connected to the charge amplifier that controls and limits the pressure ( $\max 200 \mathrm{bar}$ ). To measure the operational pressure of the engine cylinder, the piezoelectric pressure transducer is placed at the cylinder head that sends the cyclic variation of pressure as digital signals to the data acquisition system. The experiments on the laboratory engine are conducted to verify the suitability of the biodiesel at different compression ratios, for that the compression ratio of the engine is adjusted accordingly through provision at the cylinder head.

As the different combinations of biodiesel blends are used in this experimentation, the combustion required varied air intake. The air intake for the cylinder is adjusted though the supercharging unit to the inlet manifold. A centrifugal blower ( $1.5 \mathrm{~m} 3 / \mathrm{min}$ capacity) unit with flow control device is used as the supercharger that supplies the additional air to the engine during suction. A data acquisition system also 
collects the crank angle, engine speed, temperature of air inlet and exhaust, temperatures of cooling water inlet and exit, temperature of the engine, fuel flow rate, air flow rate and the $\mathrm{CO}$, NOx emissions for the performance and emission analysis. Before start of the experimentation, the test engine is allowed to operate at no load condition for 10 minutes with neat diesel as a fuel. By keeping engine at constant speed, the experiments are conducted considering the biodiesel blends (Diesel, B20-B80), compression ratio, load, injection pressure and supercharging as variables.

\subsection{Experimental Methodology}

To observe the performance and emission characteristics of the ROME biodiesel, an investigative evaluation is done on the VCR engine with different parameters as variables such that the engine performance and the emissions are set as responses. In this regard, Response surface Methodology (RSM) based experimental design matrix is developed and the experiments are conducted to develop the empirical models. The mathematical models developed are authenticated through the experiments and a hypothesis is created for the response equations. The parameters are optimized with the aim of minimizing the engine emissions with help of evolutionary multi objective optimization NSGA II.

\subsection{Error Analysis}

Poor conception, measurement flaws during experiments, inaccuracies of various equipment, and human mistakes all contribute to experimental error. Before taking the measurement, the engine operating elements and detectors are synchronized. Table.2 shows the levels of accuracy of several validated measurement devices. The error is estimated for several variables using the least measured amount and the sensitivity of the instrument. Table. 3 indicates the level of uncertainty in the investigation's various derived characteristics. The formula (Murugapoopathi \& Vasudevan 2021) is used to calculate the overall uncertainty in the computed and confirmed boundaries.

$$
\begin{gathered}
\mathrm{U}_{\text {total }}=\sqrt{ }\left\{\left(\mathrm{U}_{\mathrm{BTE}}\right)^{2}+\left(\mathrm{U}_{\mathrm{SFC}}\right)^{2}+\left(\mathrm{U}_{\mathrm{CA}}\right)^{2}+\left(\mathrm{U}_{\mathrm{EGT}}\right)^{2}+\left(\mathrm{U}_{\mathrm{CO}}\right)^{2}+\left(\mathrm{U}_{\mathrm{HC}}\right)^{2}+\left(\mathrm{U}_{\mathrm{CO} 2}\right)^{2}+\left(\mathrm{U}_{\mathrm{NOX}}\right)^{2}\right\} \\
=\sqrt{ }\left\{(1.5)^{2}+(1.4)^{2}+(1.5)^{2}+(1.4)^{2}+(1)^{2}+(1)^{2}+(2)^{2}+(2)^{2}\right\}=4.29 \%
\end{gathered}
$$

Table.2. Accuracies in measurement 


\begin{tabular}{ll}
\hline Measurements & Accuracy \\
\hline Engine speed & $\pm 11 \mathrm{rpm}$ \\
Time & $\pm 0.20 \%$ \\
Specific fuel consumption & $\pm 1 \%$ \\
Temperature & $\pm 2^{\circ} \mathrm{C}$ \\
Crank angle encoder & $\pm 0.5^{\circ} \mathrm{CA}$ \\
Piezoelectric sensor & $\pm 0.50 \%$ \\
Power & $\pm 3 \%$ \\
\hline
\end{tabular}

Table.3 Uncertainty in Measurements

\begin{tabular}{ll}
\hline Calculated parameters & Uncertainty (\%) \\
\hline BTE & 1.5 \\
SFC & 1.4 \\
Crank angle measurement & 1.5 \\
EGT & 1.4 \\
$\mathrm{CO}$ & \pm 1 \\
$\mathrm{HC}$ & \pm 1 \\
$\mathrm{CO}_{2}$ & \pm 2 \\
$\mathrm{NO}_{\bar{x}}$ & \pm 2 \\
\hline
\end{tabular}

\section{Development Of Prediction Model Using Rsm}

Biodiesel production innovations allowed for increased power output from IC engines with greater performance and lower emissions at a lower cost in current diesel engines. Implementing biodiesel in diesel engines with improved performance and emission characteristics is a big task in the current environment, and the combustion properties of biofuel are entirely connected. Engine analysis using predictive methods is designed to provide a better understanding of the parameters using simplified assumptions. Given all of the constraints, determining the genuine parameters related with engine analysis is a challenging and time-consuming operation. There is a possibility of uncertainties due to the large number of experiments performed in this technique. To circumvent these issues in trials, the design of experiments is used to develop mathematical model. The appropriate data points are chosen to create the trials, reducing the number of experiments necessary for statistics collecting. Analytical solutions may 
assess an issue and forecast the outcome with a small margin of error. As a result, statistical models based on DOE are developed to assess fuel efficiency.

The influence of critical process input variables (engine load, fuel blends, Compression ratio, Injection pressure and Supercharging) on VCR engine (Murugapoopathi \& Vasudevan 2019b) was investigated using RSM in this examination. A fractional factorial central composite design (CCD) was employed to generate 46 control parameters used to study the impact of various specified components on engine performance investigation. This was done to reduce redundancy, i.e. avoiding unnecessary repetition of experiments (Murugapoopathi et al 2018). Table 4 shows the ranges of the variables studied, which include engine load (3-9.5 kg), 19:1 to $21: 1$ compression ratio, fuel blend ratio (10\% to $30 \%), 180-200$ bar injection pressure and SC pressure (1atm. pressure bar to $1.5 \mathrm{bar}$ ).

The input data parameters were rated at low (1), medium (0), and high $(+1)$ levels, and axial points (axial distance, $a=1.414$ ) were provided to ensure that the design was orthogonal. The suggested model's lack of fit and pure error was estimated using five centre points [Myers et al 2002]. To fit the coefficient of the polynomial equation linear regression of the output, regression model were used. A significance test and analysis of variance were used to evaluate the quality of the fitted quadratic polynomial response model (ANOVA). Equation (Eq.1) shows the fitted model. The impacts of different statistical models and their combinations were quantitatively identified.

$$
Y=f\left(x_{1}, x_{2}, x_{3}, \ldots ., x_{n}\right)+\varepsilon
$$

When the first order model fails to suit the curvature of a response surface given the lack of fitting, second order models are generally applied. Because they operate well with an approximate response surface, second order models can match the curvature in a greater range of different forms. This second-order model determines the parameters and is ready to be fitted using the least-squares approach. Addressing second order models in response surface problems has a practical importance that works really well. The quadratic $\mathrm{Y}$ is a 2nd approximate solution that is represented as (Eq.2)

$$
y=\beta_{0}+\sum_{i=1}^{k} \beta_{i} X_{i}+\sum \sum_{i<j} \beta_{i j} X_{i} X_{j}+\sum_{i=1}^{k} \beta_{i j} X^{2}{ }_{i}+\varepsilon
$$

Where $\beta$ is regression constant, $k$ is the number of factor, $i$ is the linear factor, $j$ is the quadratic coefficient, $y$ is the response and $\varepsilon$ is the random error, $X_{1}, X_{2}, \ldots . . X_{k}$ are the input parameters.

\section{Table.4. The ranges of VCR engine Experimental parameters}




\begin{tabular}{llll} 
SI.No & Parameter & Min & Max \\
\hline 1. & Compression ratio (A) & 19 & 21 \\
\hline 2. & Load (B) & 3 & 9.5 \\
\hline 3. & blends (C) & 10 & 30 \\
\hline 4. & Fuel injection pressure (D) & 160 & 200 \\
\hline 5. & Supercharging (E) & $1 \mathrm{~atm}$. & 1.5
\end{tabular}

\subsection{Model Coefficients and its Importance}

MINITAB17 (Minitab is a statistical analysis tool) software is used to generate quadratic models from experimental data. The statistical software handles wide set of available data for the purpose of tasks like data consolidation, analysis, and reporting. From the past researches, the DoE is found to be more accurate, consistent, and simpler than traditional manual estimation techniques.

Table.5 RSM Design Matrix and Experimental Results 


\begin{tabular}{|c|c|c|c|c|c|c|c|c|c|c|}
\hline Run & A & B & C & D & $E$ & BTE & BSFC & $\mathrm{CO}$ & $\mathrm{HC}$ & NOx \\
\hline 1 & 20 & 6.25 & 10 & 160 & 1.25 & 35.670 & 0.259 & 0.251 & 8.9 & 391.24 \\
\hline 2 & 20 & 3 & 10 & 180 & 1.25 & 36.102 & 0.202 & 0.179 & 19.02 & 541.96 \\
\hline 3 & 21 & 6.25 & 20 & 180 & 1 & 24.752 & 0.401 & 0.289 & 14.01 & 306.40 \\
\hline 4 & 20 & 9.5 & 20 & 180 & 1.5 & 34.703 & 0.297 & 0.22 & 9.9 & 332.85 \\
\hline 5 & 20 & 6.25 & 10 & 180 & 1.5 & 17.521 & 0.695 & 0.202 & 9.2 & 216.80 \\
\hline 6 & 20 & 9.5 & 30 & 180 & 1.25 & 26.113 & 0.396 & 0.281 & 8.9 & 310.20 \\
\hline 7 & 19 & 3 & 20 & 180 & 1.25 & 23.472 & 0.382 & 0.129 & 15.2 & 221.96 \\
\hline 8 & 20 & 9.5 & 20 & 180 & 1 & 37.925 & 0.247 & 0.291 & 8.9 & 452.65 \\
\hline 9 & 20 & 6.25 & 20 & 180 & 1.25 & 23.472 & 0.382 & 0.128 & 15.2 & 223.25 \\
\hline 10 & 20 & 6.25 & 10 & 200 & 1.25 & 0.000 & 0.000 & 0.201 & 8.9 & 239.85 \\
\hline 11 & 20 & 3 & 20 & 180 & 1 & 17.826 & 0.387 & 0.311 & 11.8 & 331.66 \\
\hline 12 & 21 & 6.25 & 10 & 180 & 1.25 & 17.812 & 0.625 & 0.269 & 10.9 & 284.69 \\
\hline 13 & 21 & 6.25 & 20 & 200 & 1.25 & 23.812 & 0.526 & 0.271 & 9.2 & 264.82 \\
\hline 14 & 20 & 6.25 & 30 & 180 & 1.5 & 34.793 & 0.296 & 0.279 & 10.1 & 483.21 \\
\hline 15 & 21 & 6.25 & 20 & 160 & 1.25 & 0.000 & 0.000 & 0.188 & 14.5 & 235.69 \\
\hline 16 & 19 & 9.5 & 20 & 180 & 1.25 & 0.000 & 0.000 & 0.1298 & 8.8 & 299.22 \\
\hline 17 & 19 & 6.25 & 20 & 180 & 1.5 & 0.000 & 0.000 & 0.08 & 11.1 & 151.36 \\
\hline 18 & 20 & 6.25 & 20 & 180 & 1.25 & 26.307 & 0.340 & 0.236 & 7.6 & 297.60 \\
\hline 19 & 20 & 3 & 20 & 180 & 1.5 & 0.000 & 0.000 & 0.139 & 9.5 & 155.28 \\
\hline 20 & 20 & 6.25 & 20 & 200 & 1 & 24.702 & 0.346 & 0.11 & 8.4 & 356.51 \\
\hline 21 & 19 & 6.25 & 10 & 180 & 1.25 & 24.941 & 0.365 & 0.122 & 13.9 & 297.86 \\
\hline 22 & 19 & 6.25 & 20 & 200 & 1.25 & 25.069 & 0.399 & 0.171 & 11.1 & 262.80 \\
\hline 23 & 20 & 6.25 & 10 & 180 & 1 & 18.536 & 0.578 & 0.195 & 9.9 & 162.57 \\
\hline 24 & 19 & 6.25 & 30 & 180 & 1.25 & 17.427 & 0.588 & 0.259 & 5.9 & 343.40 \\
\hline 25 & 21 & 6.25 & 20 & 180 & 1.5 & 24.229 & 0.321 & 0.18 & 3.6 & 371.69 \\
\hline 26 & 21 & 9.5 & 20 & 180 & 1.25 & 23.797 & 0.390 & 0.226 & 30 & 283.80 \\
\hline 27 & 20 & 6.25 & 20 & 180 & 1.25 & 25.925 & 0.390 & 0.151 & 0.6 & 243.65 \\
\hline 28 & 19 & 6.25 & 20 & 180 & 1 & 14.144 & 0.688 & 0.375 & 28.5 & 229.63 \\
\hline
\end{tabular}




\begin{tabular}{|lllllllllll|}
\hline 29 & 20 & 3 & 20 & 200 & 1.25 & 0.000 & 0.000 & 0.168 & 8.9 & 219.56 \\
\hline 30 & 21 & 6.25 & 30 & 180 & 1.25 & 0.000 & 0.000 & 0.091 & 5.5 & 156.32 \\
\hline 31 & 20 & 9.5 & 10 & 180 & 1.25 & 23.472 & 0.382 & 0.126 & 15.2 & 221.68 \\
\hline 32 & 20 & 6.25 & 20 & 180 & 1.25 & 23.499 & 0.348 & 0.109 & 14.6 & 296.40 \\
\hline 33 & 20 & 6.25 & 20 & 180 & 1.25 & 23.472 & 0.390 & 0.126 & 15.3 & 221.99 \\
\hline 34 & 21 & 3 & 20 & 180 & 1.25 & 25.321 & 0.386 & 0.155 & 1.2 & 235.62 \\
\hline 35 & 20 & 6.25 & 20 & 180 & 1.25 & 23.956 & 0.598 & 0.299 & 8.6 & 299.85 \\
\hline 36 & 20 & 3 & 30 & 180 & 1.25 & 23.216 & 0.409 & 0.231 & 7.6 & 255.67 \\
\hline 37 & 20 & 9.5 & 20 & 160 & 1.25 & 23.472 & 0.382 & 0.126 & 15.2 & 221.69 \\
\hline 38 & 20 & 6.25 & 20 & 160 & 1 & 31.265 & 0.307 & 0.369 & 17.6 & 375.00 \\
\hline 39 & 20 & 9.5 & 20 & 200 & 1.25 & 25.621 & 0.379 & 0.236 & 12.5 & 368.94 \\
\hline 40 & 20 & 3 & 20 & 160 & 1.25 & 36.608 & 0.265 & 0.232 & 7.4 & 439.87 \\
\hline 41 & 20 & 6.25 & 30 & 160 & 1.25 & 23.341 & 0.476 & 0.271 & 1.5 & 285.63 \\
\hline 42 & 20 & 6.25 & 30 & 200 & 1.25 & 0.000 & 0.000 & 0.231 & 15.9 & 142.36 \\
\hline 43 & 20 & 6.25 & 20 & 160 & 1.5 & 29.624 & 0.328 & 0.259 & 10.1 & 253.16 \\
\hline 44 & 20 & 6.25 & 30 & 180 & 1 & 24.014 & 0.396 & 0.119 & 13.1 & 333.66 \\
\hline 45 & 19 & 6.25 & 20 & 160 & 1.25 & 28.982 & 0.365 & 0.231 & 12.8 & 236.40 \\
\hline 46 & 20 & 6.25 & 20 & 200 & 1.5 & 23.472 & 0.382 & 0.129 & 15.2 & 221.64 \\
\hline
\end{tabular}

The experiment is designed with 46 runs for five factors and three levels using the central composite design. The experiment was conducted based on design matrix and output responses were recorded. The factors influence the responses are correlated. The predicted equation is framed based on influencing parameters with $95 \%$ confidence. The adequacy of model is tested and presented in Table 5 . The $p$ value represents the degree of confidence of coefficients. The correlations are assessed for the relevance at a $95 \%$ level of certainty. With each component, $p$ values less than 0.05 are deemed relevant. When a $p$ value exceeds 0.05 , it is considered insignificant and is omitted from the predictable equation. All lower order polynomials should be present for the model construction principle, and the term $\mathrm{C}$ in $\mathrm{CO}$ and term $\mathrm{E}$ in NOx are added to protect the model hierarchy (Myers et al. 2002).

\subsection{Model testing and Evaluation}

The ANOVA table findings are used to test the model's suitability and validity, and the predictive data values are listed in Table 6 . The $\mathrm{R}^{2}$ coefficient of determination obtained from the regression variables in the model minimizes the variation in the response parameter. When the $\mathrm{R}^{2}$ number is 1 , the model 
completely matches the data, and the residuals drop as the $\mathrm{R}^{2}$ value lowers. Conversely, by adding more variables to the model, the $\mathrm{R}^{2}$ effect is enhanced, but this does not indicate out whether level of significance. As a result, for a more precise model, the correlation metrics employs the corrected $\mathrm{R}^{2}$ value. The prediction data values of $R^{2}$ and $R^{2}$ adj. of performance, emission, and combustion pressure are nearer together and accord well with the predictive statistics approach shown in Table.7. The scientific model's forecasting characteristics are tested for 46 runs using research observations and evaluated. The results show that the projected values match the observational evidence quite well.

Table.6 Model Adequacy for Responses $\mathrm{CO}$ and NOx. 


\begin{tabular}{|c|c|c|c|c|c|c|}
\hline \multicolumn{3}{|c|}{ Coefficients of CO } & \multicolumn{3}{|c|}{ Coefficients of $\mathrm{NO}_{\mathrm{x}}$} & \multirow[t]{2}{*}{ Parameter Significancy } \\
\hline Term & Coefficient & $\mathrm{p}$ value & Term & Coefficient & $p$ value & \\
\hline Constant & 0.000 & 0.000 & Constant & 9957.798 & 0.008 & significant \\
\hline A & 0.000 & 0.000 & $A$ & -332.64 & 0.020 & significant \\
\hline B & 0.000 & 0.000 & B & 363.03 & 0.000 & significant \\
\hline C & $0.063^{\star}$ & 0.000 & $\mathrm{C}$ & 14.63 & 0.029 & significant \\
\hline D & 0.000 & 0.000 & $\mathrm{D}$ & -82.96 & 0.018 & significant \\
\hline E & 0.001 & 0.000 & E & -1681.23 & $0.164^{*}$ & insignificant \\
\hline$A^{2}$ & 0.000 & $0.061^{*}$ & $A^{2}$ & 9.74 & 0.005 & significant \\
\hline$B^{2}$ & 0.000 & 0.000 & $B^{2}$ & 3.55 & 0.000 & significant \\
\hline$c^{2}$ & 0.000 & $0.111^{\star}$ & $c^{2}$ & 0.02 & 0.002 & significant \\
\hline$D^{2}$ & 0.000 & 0.000 & $D^{2}$ & 0.29 & 0.007 & significant \\
\hline$E^{2}$ & 0.000 & 0.000 & $E^{2}$ & 403.46 & 0.014 & significant \\
\hline$A B$ & 0.000 & 0.000 & $A B$ & -3.52 & $0.169 *$ & insignificant \\
\hline$A C$ & 0.000 & 0.000 & $A C$ & -0.5 & 0.009 & significant \\
\hline$A D$ & 0.001 & 0.000 & $A D$ & -0.10 & $0.878^{*}$ & insignificant \\
\hline $\mathrm{AE}$ & 0.009 & 0.000 & $\mathrm{AE}$ & -34.04 & $0.301^{*}$ & insignificant \\
\hline BC & 0.000 & 0.000 & $\mathrm{BC}$ & -0.5 & 0.000 & significant \\
\hline BD & 0.000 & 0.000 & $\mathrm{BD}$ & -1.84 & 0.000 & significant \\
\hline BE & 0.000 & 0.000 & $\mathrm{BE}$ & 5.34 & $0.664^{*}$ & insignificant \\
\hline CD & $0.063^{*}$ & 0.000 & CD & -0.02 & 0.426 & significant \\
\hline CE & 0.000 & 0.000 & CE & -6.02 & 0.000 & significant \\
\hline DE & 0.001 & 0.000 & $\mathrm{DE}$ & 15.11 & 0.028 & significant \\
\hline
\end{tabular}

Table.7. Model Adequacy for fitting the polynomial model 


\begin{tabular}{|c|c|c|c|c|c|}
\hline Model & $\begin{array}{l}\text { BTE } \\
\text { (\%) }\end{array}$ & $\begin{array}{l}\text { BSFC } \\
\text { (kg/kWh) }\end{array}$ & $\begin{array}{l}\text { CO } \\
(\%)\end{array}$ & $\begin{array}{l}\mathrm{HC} \\
\text { (ppm) }\end{array}$ & $\begin{array}{l}\mathrm{NO}_{x} \\
(\mathrm{ppm})\end{array}$ \\
\hline$p$-value & $\bowtie 0.0001$ & $\bowtie 0.0002$ & $\bowtie 0.0001$ & 0.0002 & 0.0001 \\
\hline SD & 11.052 & 0.18707 & 0.07373 & 5.6714 & 87.533 \\
\hline Mean & 21.052 & 0.33236 & 0.20371 & 11.342 & 284.31 \\
\hline $\mathrm{R}^{2}$ & 0.9888 & 0.9852 & 0.9992 & 0.9963 & 0.9866 \\
\hline $\operatorname{Adj} . R^{2}$ & 0.9798 & 0.9734 & 0.9986 & 0.9933 & 0.9758 \\
\hline
\end{tabular}

\section{Nsga li Optimization Of Engine Emissions}

In the recent days, engineering problems are highly entangled with more number of conflicting objectives, constraints and are expected to be solved with number of optimized solutions. Handling such problems and finding the solution for such kind problems is highly challenging and require more computation time. This makes the designers/researcher to opt the multi-objective optimization with a set diversified population of variables and to eliminate the pre-matured convergence of the pareto optimal solution. In general, problems with multi-objectives need to be optimized develop more pareto optimal solutions (Castresana, $\mathrm{J}$ et al. 2021). The expectations from the evolutionary multi-objective algorithms are provide the maximum possible Pareto optimal solutions and their subsets. Also, the pareto optimal solutions should confirm the uniform distribution of the optimal fronts which will make the researchers to go for the right decision making when the problems have multi and contradictory objectives. Out of many multiobjective optimization techniques, NSGA-II has proved satisfactory results due to their inherent ability of solving continuous and discontinuous problems. The NSGA-II based optimization algorithm is most popularly used evolutionary optimization algorithm for multi-objective solutions in engineering applications. As it uses the non-dominated solutions and trade off the difficulties in achieving the conflicting multiple conflicting objectives. Also is uses the elitism concept that explicitly preserves the diversity of the solutions with help of non-dominated solutions. The method of non-dominated sorting and crowding distance, crossover and mutations make the NSGA-II as proven optimization technique. For the next generation selection, the method of elitism is used by keeping the fittest chromosome for subsequent generations.

\subsection{The Process of NSGA-II}

In this article, the NSGA-II used for the optimizing the engine parameters to minimize the exhaust emissions. The parameters stated for this problem initiated with a set of populations have randomly generated binary numbers. The each set of population is a chromosome and the length of binary numbers is 60 considering every subsequent 12 positions for each variable (Table.8). The length of binary number is defined based on the requirement of approximation and are converted in to real numbers of each 
individuals (Eq.3) within the range considered. For the process of selection, the fitness value for individual is determined from objective function and the Pareto ranking is applied to achieve the new generation.

$v_{\text {ram }}=$ range $_{\min }+\frac{\left(\text { range }_{\max }-\text { range }_{\min }\right)}{\left(2^{n}-1\right)} v_{\text {biv }}$

Where,

$v_{\text {Num }}-$ Numerical value of the variable

$v_{\text {bin }} \quad-$ binary value of the variable

range $_{\min }-$ minimum range of the variable

range $_{\max }-$ maximum range of the variable

Table.8 Sample Binary Chromosome for the initial population

\begin{tabular}{|llllll|}
\hline Variable & $\begin{array}{l}\text { Compression } \\
\text { Ratio }\end{array}$ & Load & Blend & Pressure & Super Charging \\
\hline CR & L & BL & $\boldsymbol{P}$ & SC \\
\hline Numeric & 20 & 8 & 40 & 150 & 0.5 \\
\hline Binary & 010010001001 & 101111000111 & 110101110110 & 010101011001 & 011010110110 \\
\hline
\end{tabular}

The pareto front of the dominating individual chromosome is verified and the subsequent Pareto front is generated by the dominating individuals. This process is continued till the new individuals are replaced with new fronts with good rankings. The ranking for the individual is processed through the crowding distance, which provides uniform distribution of the pareto front. To determine the cluster of local optima solutions after the selection process, the production of the off springs, the parent selection is carried out through the crossover process (Fig.2). The single point cross over is executed with through random location on binary chromosome with a probability between 0.65 and 0.8 .

As a continuation of cross over, NSGA II has the provision to determine the global optima from for which the solution is left out of the cluster. It finds the possible solutions just outside the range just by modifying the quality of one/two/multiple gene(s). For that the multipoint mutation process (Fig.3), with the probability between 0.05 and 0.07 , is used in which the binary numbers are muted between zero and one. At the end of the mutation process the population is sorted and fittest individuals are retained. The NSGA process continues until the termination criteria reach the specified iterations.

\subsection{NSGA II Results of Engine Emissions}


The NSGA II for this multi objective engine emission optimization problem executed such that the design variables are the Compression ratio $(C R)$, Load $(L)$, Blend $(B L)$, Injection pressure $(P)$ and the Supercharging percent $(\mathrm{SC})$ and the objectives for the optimization is the engine emissions ( $\mathrm{CO}$ and $\mathrm{NO}_{\mathrm{x}}$ ). In which the empirical relation used for determining the objective functions are obtained from the statistical technique "Design of Experiments" and are the function of the design variables defined for this emission problem. A set of 40 population, containing the design variables, for the optimization is generated from the range defined for each variable. The number of the generations are continued up to 100 which is the termination criteria for this optimization. The following is the pseudo code for the NSGA Il simulation for optimization.

Input: Population $(P)$, Number of Generations $(n)$, Objective functions $\left(f\left(x_{1}\right), f\left(x_{2}\right)\right)$

Initialise the population ' $P$ '

Determine the values of Objectives and fitness values

for $i=1$ to $n$

Rank the population on Pareto ranking through nondominated solutions

Determine the crowding distance

perform parent selection

perform the Crossover

perform the mutation

keep the best individual for next generation (elitism)

end

termination of the loop

The results from the optimization are obtained after 100 generations are tabulated here under Table. 9 and the graph (Fig.4) shows the convergence of objective function for every generation.

\section{Discussion On Results}

\subsection{Results discussion on emission characteristics}

The emission characteristics of VCR engine was analysed for $80 \%$ load at constant speed of $1500 \mathrm{rpm}$. The $\mathrm{CO}$ and $\mathrm{NO}_{\mathrm{x}}$ emission under varying compression ratios for various fuel blends are presented in Fig.5. The $\mathrm{CO}$ emissions are decreased with increase in CR. The $\mathrm{CO}$ emission for diesel, B20 and B40 decreases with increase in $\mathrm{CR}$. The compression ratio proportionally raises the gas temperature and atomizes the 
fuel particle during combustion at maximum load. At the same time, higher viscosity of B60 and B80 increases $\mathrm{CO}$ emission due to poor mixing. Conversely, the $\mathrm{NO}_{x}$ emission of $\mathrm{B} 20$ and $\mathrm{B} 40$ are comprehend with that diesel due to better atomization and rise in in-cylinder temperature for higher CR 20. The optimum emission (CO\& $\mathrm{NO}_{\mathrm{x}}$ ) results are obtained for $\mathrm{CR} 20$ at $80 \%$ load for $\mathrm{B} 20$ and $\mathrm{B} 40$ with that diesel in VCR engine. The $\mathrm{CO}$ and NOx emission of various biodiesel blends under combination of FIP are given in Fig.6. The fuel injector sprays fuel at high velocity in the engine cylinder for proper air-fuel mixing. The advance in FIP speeds up the atomization process at higher velocity. The $\mathrm{CO}$ emission of B20 and B40 is less than that of diesel at 180 and 200 bar FIP compared to nozzle opening pressure. This achieved by lower the viscosity and higher injection pressure of $\mathrm{B} 20$ and $\mathrm{B} 40$. At the same time, the $\mathrm{NO}_{\mathrm{x}}$ emission increases slightly with increase in FIP for B20 and diesel but comparable with that diesel. The optimum $\mathrm{CO}$ and $\mathrm{NO}_{\mathrm{x}}$ emission at $180 \mathrm{bar}$ are comparable with that diesel for $\mathrm{B} 20$ and $\mathrm{B} 40$ compared to higher blends. There is no significant improvement found for higher blends due to higher viscosity at different operating pressure. Supercharging is the process of boosting the inlet air through blower to provide excess air during combustion. Boosting inlet air improved the combustion and decreases the $\mathrm{HC}$ and $\mathrm{CO}$ emission significantly.

The boost pressure are 1atm, 1.25 bar and 1.5 bars varied at inlet flow conditions for various biodiesel blends are depicted in Fig.7. Mostly in $\mathrm{Cl}$ engine, $\mathrm{HC}$ emission and $\mathrm{CO}$ emission is increased with insufficient air to catch air pockets in the chamber. The $\mathrm{CO}$ emission of B20 and B40 is decreased with increase in boost pressure in the cylinder at 0.25 bar and 0.5 bar gauge pressure at inlet manifold compared to atmospheric pressure. The NOx emission is slightly increased with supercharging for B20 and B40in comparison with diesel due to raise in cylinder temperature at higher $\mathrm{CR}$, load and supercharging. The SC pressure 1.5 bar provided the optimum emission results compared to that diesel in VCR engine analysis.

The $\mathrm{CO}$ and $\mathrm{NO}_{\mathrm{x}}$ emission of various ROME blends at combination of loads are shown in Fig.8. The increase in load decreases the $\mathrm{CO}$ emission of all fuel blends compared to diesel except B60 and B80. CO emission of B60 and B80 are higher than diesel due to higher viscosity and poor atomization. The $\mathrm{CO}$ emission of B20 and B40 are higher up to $2 \mathrm{~kg}$ due to incomplete combustion and lower cylinder temperature. The $\mathrm{CO}$ emission is greatly decreased for B20 and B40 at increase in load due to oxygen molecules present in the biodiesel and cylinder temperature (Leo et.al 2021). The cylinder temperature increases with load with increase the NOx emission considerably for all the fuel blends. But the NOx emission of B20 and B40 are comparable with that of diesel at all operating conditions. The ROME blends of B20 and B40 improved the performance and lower the emission at improved CR, FIP and supercharging at maximum load.

\subsection{Emission characteristics on Predicted results}

Figure 9 shows a plot of $\mathrm{CO}$ and NOx emission predictable values versus experimental data. The standard error is a metric for determining how accurate predicted values are. The square root of the average squared deviation is the regression line that minimises the sum of squared deviations of the anticipated

Page $18 / 27$ 
one and standard error. The regression analysis output is the standard error of the slope. The $R^{2}$ value of the estimated $\mathrm{CO}$ emission model is 0.99908 , while the standard error is 0.0054 . The largest difference between predicted and experimental $\mathrm{CO}$ models is determined to be 0.004757 percent. The $\mathrm{R}^{2}$ value achieved with the projected model is 0.98341 closer to unity, which is consistent with the experimental results. The regression of $\mathrm{NO}_{x}$ emission is observed to be 0.023 , with a variation of $11 \mathrm{ppm}$ from the predicted model. This is due to biodiesel's complex combustion mechanism, which includes a high compression ratio and long ignition latency. For the entire run of investigations, the foregoing results demonstrated that the expected emission parameter is effectively fitted to VCR engine response.

\subsection{Results on NSGA II}

The objective optimization in NSGA II was performed for on the engine emission parameters considering Compression ratio, Load, blend, Fuel injection pressure, and Supercharging as decision variables. The approximate results were arrived from the number of nondominated solutions provided by the algorithms in the final approximated optimal sets. It was being noticed that the proposed configuration in the reproduction process increased the search capabilities of both NSGA-Il with respect to the standard configuration. The of cross-over and mutation are performed on the populated individuals with the probability ranges of $0.65-0.85$ and $0.01-0.02$ to determine the feasible local and global optima. In particular, NSGA-II was able to find the better individual sets of optimal solutions with a pre-defined threshold of 40 individuals. This evolutionary method produced approximate efficient fronts with the smallest spacing. But, according to the type of variables and the responses, the complexity in the standard mode of NSGA II algorithms may arise and will require little more attention on the reproduction of the individuals.

The proposed NSGA II has been applied in this research work is capable of optimizing the engine parameters to minimize the emissions from the engine. The optimization method is well considered to identify the effect of variations in the input variables of the factors on responses. The results of optimized variables obtained from the optimization was tested experimentally on the laboratory engine and the convergence of the results showed that the recommended optimal amount of emissions and are close to the results of the NSGA II. The best individual obtained from the NSGA II is given in table. 9 depicts the least emissions are possible from the combustion of biodiesel-diesel blends. These values, experimental and numerical, are compared (Table 9 ) and are found to be $2 \%$ of variation for $\mathrm{CO}$ and $1.79 \%$ of variation for the NOx and these are variations in acceptable range for engine optimization with high complexity of parameters. The performance of optimal parameters on the BTE and BSFC are found to be good enough to justify the variables and also the combustion emissions.

\section{Table.9. Validation of NSGA II Optimised results of Engine Emissions with Experiments}




\begin{tabular}{|cllllllllll|}
\hline \multicolumn{3}{|c}{ Design variables } & \multicolumn{4}{c}{ Results of GA } & \multicolumn{3}{c|}{ Experimental Results } \\
\hline $\mathrm{CR}$ & $\mathrm{L}$ & $\mathrm{BL}$ & $\mathrm{P}$ & $\mathrm{SC}$ & $\mathrm{CO}$ & $\mathrm{NO}_{\mathrm{x}}$ & $\mathrm{CO}$ & $\mathrm{NO}_{\mathbf{x}}$ & $\mathrm{BTE}$ & $\mathrm{BSFC}$ \\
& $\mathrm{kg}$ & $\%$ & bar & $\mathrm{bar}$ & $\%$ & $\mathrm{ppm}$ & $\%$ & $\mathrm{ppm}$ & $\%$ & $\mathrm{Kg} / \mathrm{kWh}$ \\
\hline 20 & 9.5 & 20 & 180 & 1.5 & 0.054871 & 221.0935 & 0.056 & 225.13 & 36.56 & 0.2381 \\
\hline
\end{tabular}

\section{Conclusion}

The emission characteristics of VCR engine was analysed under varying CR, load, blend, IP and SC on the VCR engine with ROME Biodiesel and its blends considering the performance and the emission parameters as variables. The $\mathrm{CO}$ and $\mathrm{NO}_{x}$ emission were majorly focussed and analysed under varying operating condition for ROME biodiesel blends as they contribute more on the polluting the environment. From the interpretation of experimental results, the optimum $\mathrm{CO}$ and $\mathrm{NO}_{\mathrm{x}}$ emission were found for $\mathrm{CR} 20$, FIP 180 bar and supercharging pressure 1.5 bar at maximum load. The $\mathrm{CO}$ emission is mainly due to incomplete combustion of fuel particles due to poor mixture of air-fuel, insufficient air, and lesser injection pressure and in-cylinder temperature. These experimental observations addressed the above issues to find the optimum operating conditions by interpreting various factors through RSM and NSGA II. The experimental results are interpreted using ANOVA table and results of RSM are used to find the numerical equation.

The proposed NSGA II has been applied in this research work is capable of optimizing the engine parameters to minimize the emissions from the engine. The optimization method is well considered to identify the effect of variations in the input variables on the responses. The optimized variables obtained from proposed NSGA II was tested experimentally. The results of experiment test for the optimal parameters on the engine and the convergence of the results are close to the results of the NSGA II. The emissions released corresponding is found to fall under recommended optimal amount of emissions. In accordance with optimal parameters the performance characters the BTE and the BSFC are found to be $36.56 \%$ and $0.2381 \mathrm{~kg} / \mathrm{kWh}$ which are quit good results for the biodiesel operated engines compared with diesel.

The $\mathrm{CO}$ and $\mathrm{NO}_{\mathrm{x}}$ emissions for the B20 biodiesel-diesel blend at $9.5 \mathrm{~kg}$ load, CR 20 with FIP 180 bar and 1.5 bar supercharged condition (NSGA II optimized engine parameters) were found to be $0.056 \%$ and $225.13 \mathrm{ppm}$. Subsequently, the $\mathrm{CO}$ and $\mathrm{NO}_{\mathrm{x}}$ emission of $\mathrm{B} 20$ reduced by $62.91 \%$ and $29.86 \%$ compared with neat diesel. It shows the better reduction in the $\mathrm{CO}$ and $\mathrm{NO}_{\mathrm{x}}$ compared with rest of the operating conditions. The contribution of this research work clearly emphasising on the reduction of the emissions from the diesel engine which was observed in the comparison of neat diesel and B20 blend. This comparison clearly depicts that diesel blended with biodiesel have great influence on the environment control emission. Without altering the optimized engine parameters, the improvements in increase in performance and reduction emission will be possible. 


\section{Declarations}

\section{Ethical Approval and Consent to Participate}

Not Applicable

\section{Consent to Participate}

Not Applicable

\section{Consent to Publish}

Not Applicable

As the data and images presented in the manuscript are solely prepared by the authors.

\section{Authors Contributions}

Ramachandran performed analysis on the statistical methods used in this research/manuscript. Murugapoopathi prepared biodiesel and diesel-ROME blends also carried out the laboratory test for the properties of blends. Dharmalingam conducted experiments on the VCR engine according to the design matrix generated. Surendarnath is contributor in writing the manuscript, done the proofing and plagiarism check.

All authors read and approved the final manuscript

\section{Funding}

There are no funding bodies/agencies involved in this research work and is solely contributed by the authors.

\section{Competing Interests}

The authors declare that they have no competing interests

\section{Availability of data and materials}

Not Applicable

\section{References}

Aghbashlo, M., Peng, W., Tabatabaei, M., Kalogirou, S. A., Soltanian, S., Hosseinzadeh-Bandbafha, H., \& Lam, S. S. (2021). Machine learning technology in biodiesel research: A review. Prog. Energy Combust. Sci., 85, 100904. 
Bielaczyc, P., \& Woodburn, J. (2019). Trends in automotive emission legislation: impact on LD engine development, fuels, lubricants and test methods: a global view, with a focus on WLTP and RDE regulations. Emission Contr. Sci. Technol., 5(1), 86-98

Borror, C. M., Montgomery, D. C., \& Myers, R. H. (2002). Evaluation of statistical designs for experiments involving noise variables. J. Qual. Technol.,34(1), 54-70.

Castresana, J., Gabiña, G., Martin, L., \& Uriondo, Z. (2021). Comparative performance and emissions assessments of a single-cylinder diesel engine using artificial neural network and thermodynamic simulation. Appl. Therm. Eng., 185, 116343.

Debnath, R., Sastry, G. R. K., \& Rai, R. N. (2019). An experimental investigation of performance and emission of thumba biodiesel using butanol as an additive in an IDI Cl engine and analysis of results using multi-objective fuzzy-based genetic algorithm. Environ. Sci. Pollut. Res., 26(3), 2281-2296.

Hoang, A. T., Nižetić, S., Ong, H. C., Tarelko, W., Le, T. H., Chau, M. Q., \& Nguyen, X. P. (2021). A review on application of artificial neural network (ANN) for performance and emission characteristics of diesel engine fueled with biodiesel-based fuels. Sustain. Energy Technol. Assess., 47, 101416.

Leo, G. L., Thodda, G., \& Murugapoopathi, S. (2021). Experimental investigation on effects of gasoline premixed-Al2O3 additive blended fish oil biodiesel fuelled HCCI-DI engine. J. Phys. Conf. Ser. 2054(1), 012040.

Murugapoopathi, S., \& Vasudevan, D. (2019a). Energy and exergy analysis on variable compression ratio multi-fuel engine. J. Therm. Anal. Calorim., 136(1), 255-266.

Murugapoopathi, S., \& Vasudevan, D. (2021a). Experimental and numerical findings on VCR engine performance analysis on high FFA RSO biodiesel as fuel using RSM approach. Heat and Mass Transf, 57(3), 495-513.

Murugapoopathi, S., Vasudevan, D., \& Karthikeyan, S. (2019c). Prediction of performance and emission characteristics of biodiesel blends-response surface methodology approach. AIP Conf Proc 2161 (1). 020014.

Murugapoopathi, S., Vasudevan, D., \& Rajaganapathy, C. (2021b). Investigation on VCR engine performance using (Hevea brasiliensis) biodiesel using response surface method. Mater. Today: Proc., 37, 1096-1102.

Murugapoopathi, T. R., \& Vasudevan, D (2018). RSM based Empirical Model for the Performance and Emission Characteristics of ROME Biodiesel. ratio, 4(0).

Murugapoopathi, S., \& Vasudevan, D. (2019b). Performance, combustion and emission characteristics on VCR multi-fuel engine running on methyl esters of rubber seed oil. J. Therm. Anal. Calorim., 138(2), 13291343. 
Onoji, S. E., lyuke, S. E., Igbafe, A. I., \& Nkazi, D. B. (2016). Rubber seed oil: A potential renewable source of biodiesel for sustainable development in sub-Saharan Africa. Energy Convers. Manag. , 110, 125-134.

Pour, A. H., Ardebili, S. M. S., \& Sheikhdavoodi, M. J. (2018). Multi-objective optimization of diesel engine performance and emissions fueled with diesel-biodiesel-fusel oil blends using response surface method. Environ. Sci. Pollut. Res., 25(35), 35429-35439.

Simsek, S., Uslu, S., \& Simsek, H. (2021). Proportional impact prediction model of animal waste fat-derived biodiesel by ANN and RSM technique for diesel engine. Energy, 122389.

Thulasiram, R., Murugan, S., Ramasamy, D., \& Sundaramoorthy, S. (2021). Modelling and evaluation of combustion emission characteristics of COME biodiesel using RSM and ANN-a lead for pollution reduction. Environ. Sci. Pollut. Res., 1-12.

Uslu, S. (2020). Optimization of diesel engine operating parameters fueled with palm oil-diesel blend: Comparative evaluation between response surface methodology (RSM) and artificial neural network (ANN). Fuel, 276, 117990.

Vellaiyan, S., Subbiah, A., \& Chockalingam, P. (2019). Multi-response optimization to obtain better performance and emission level in a diesel engine fueled with water-biodiesel emulsion fuel and nanoadditive. Environ Sci Pollut Res, 26(5), 4833-4841.

\section{Figures}

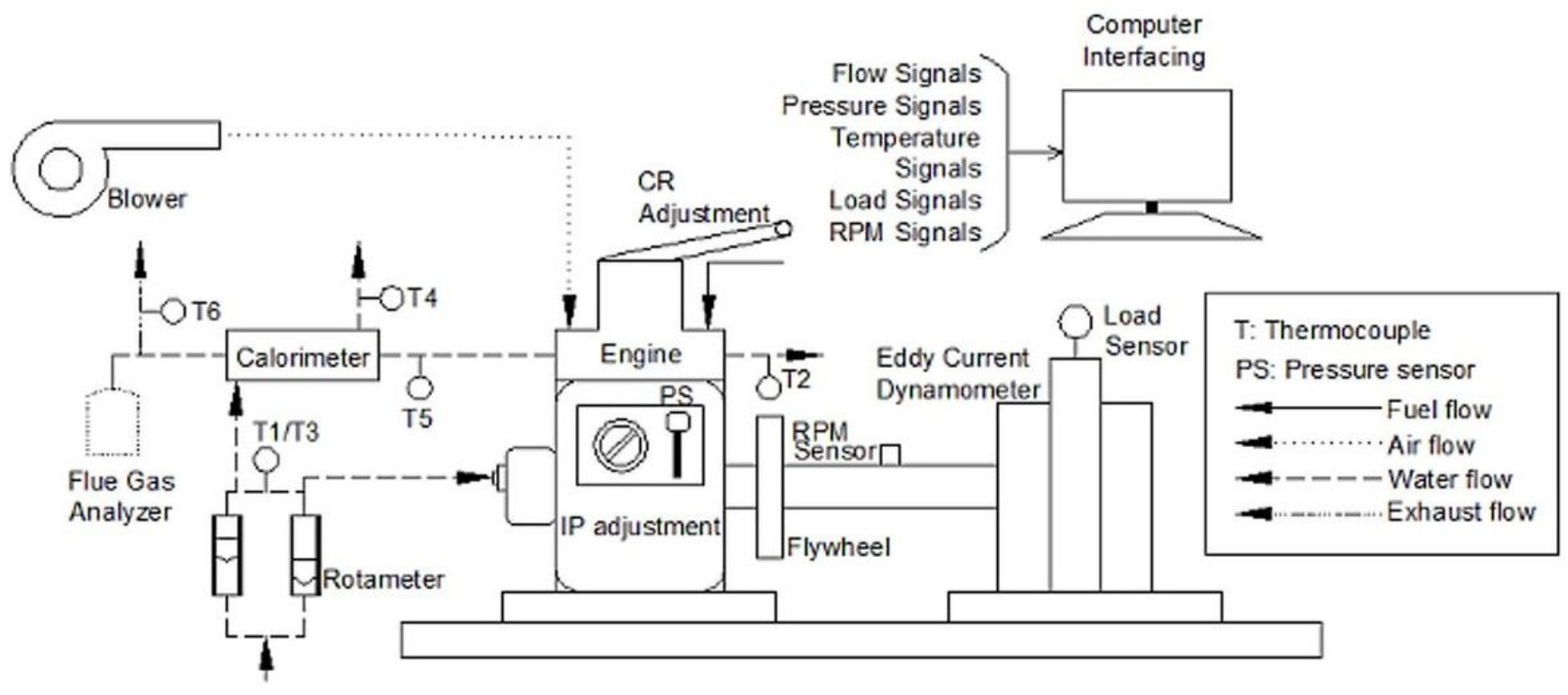

Figure 1 


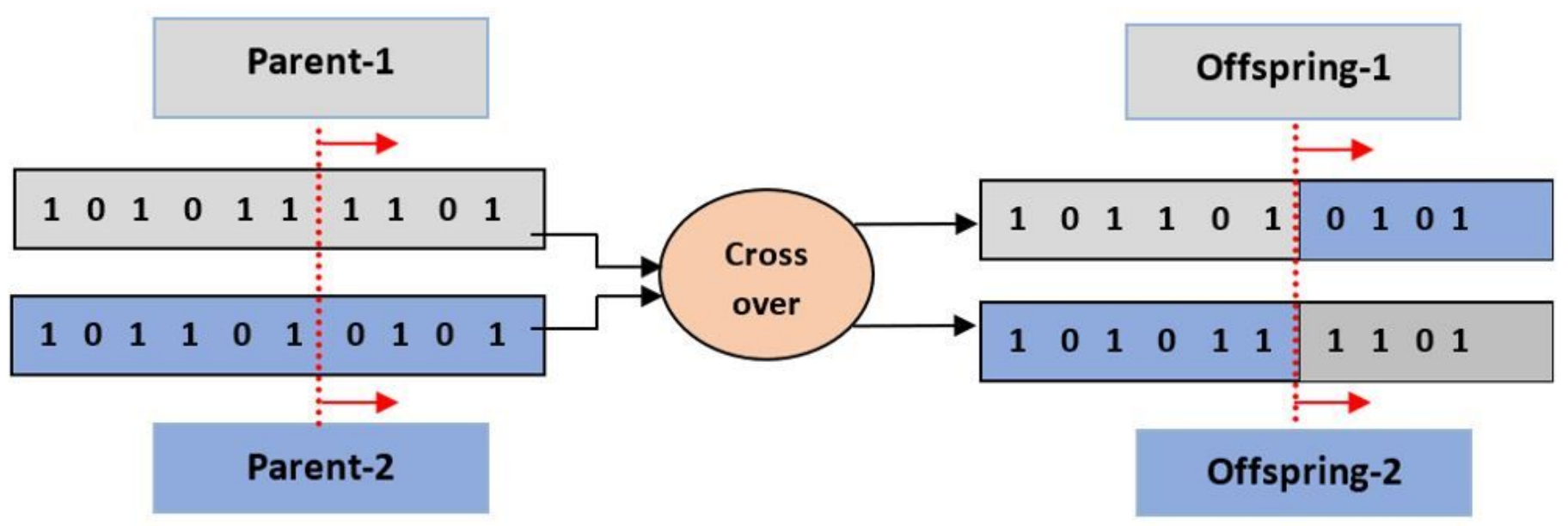

Figure 2

Example of Single point Crossover of the Parent

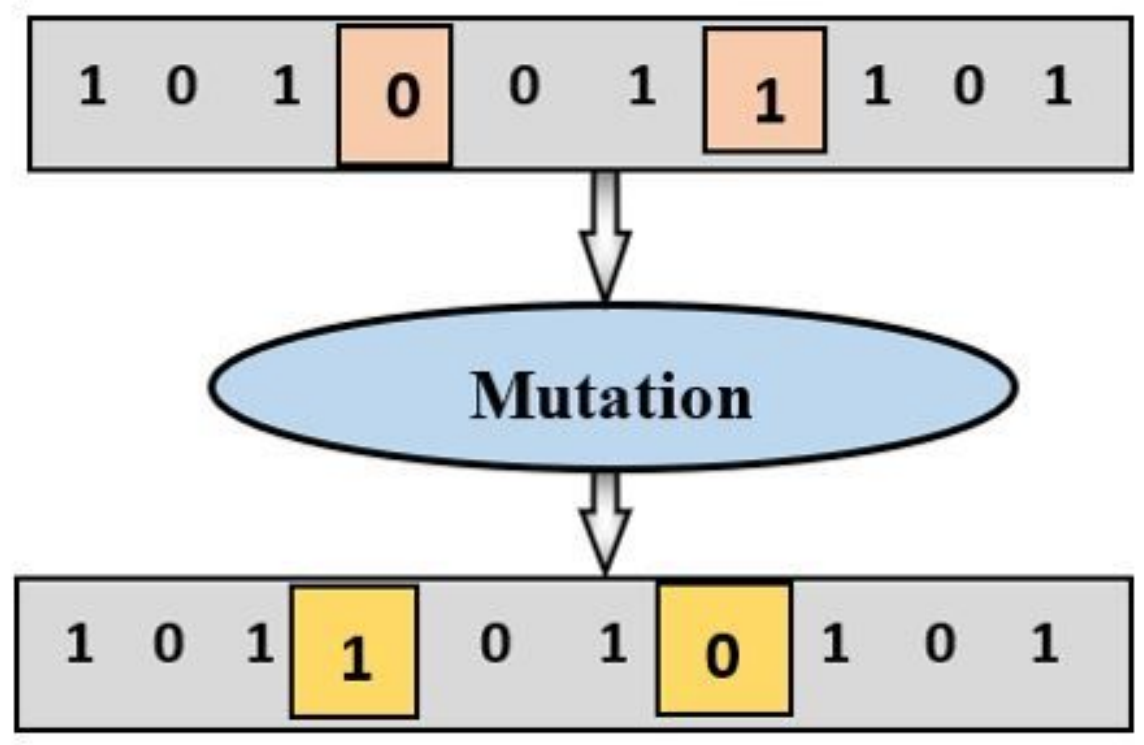

Figure 3

Multipoint Mutation of the individuals 


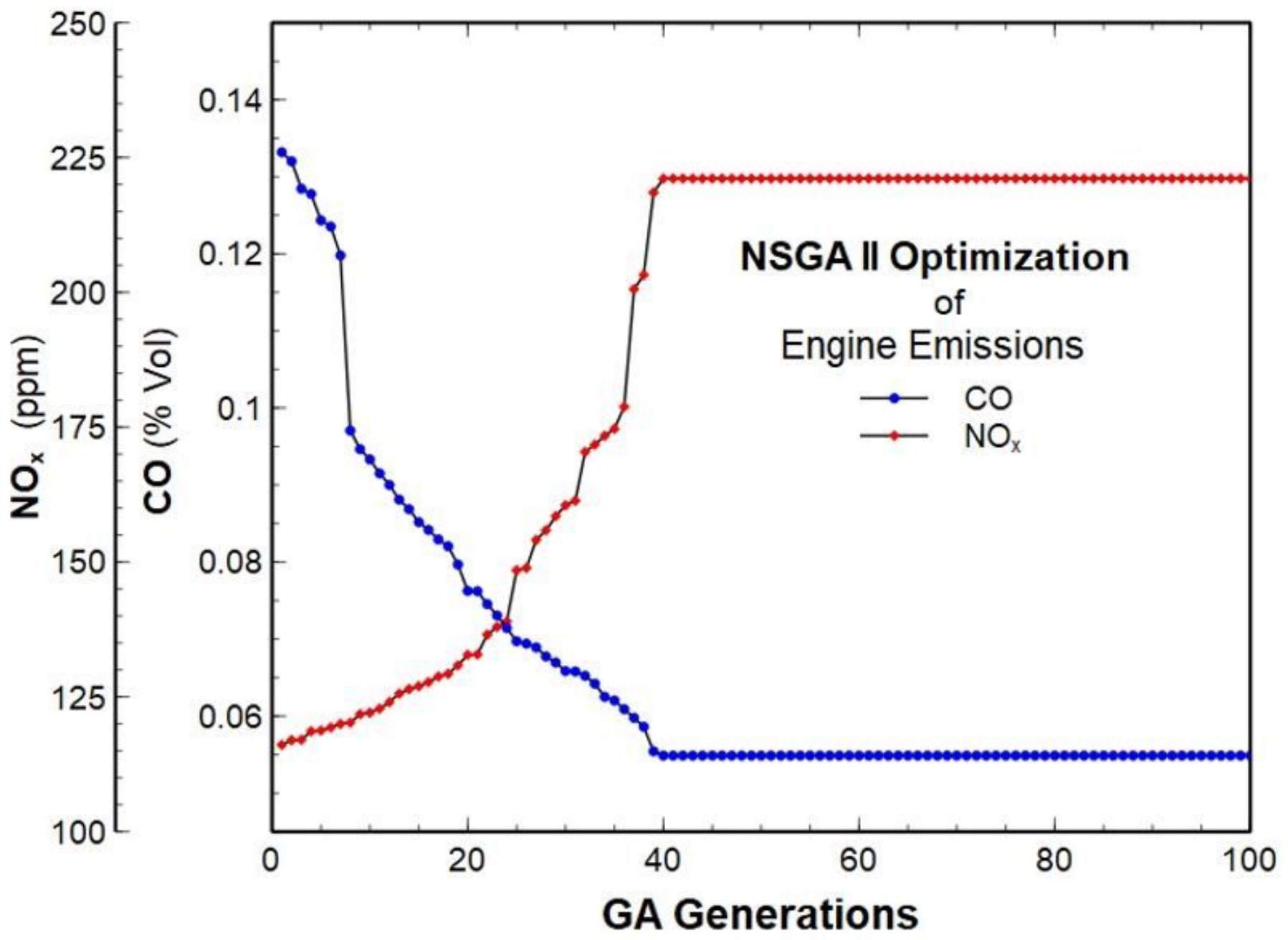

Figure 4

Convergence results of NSGA II for emission parameters
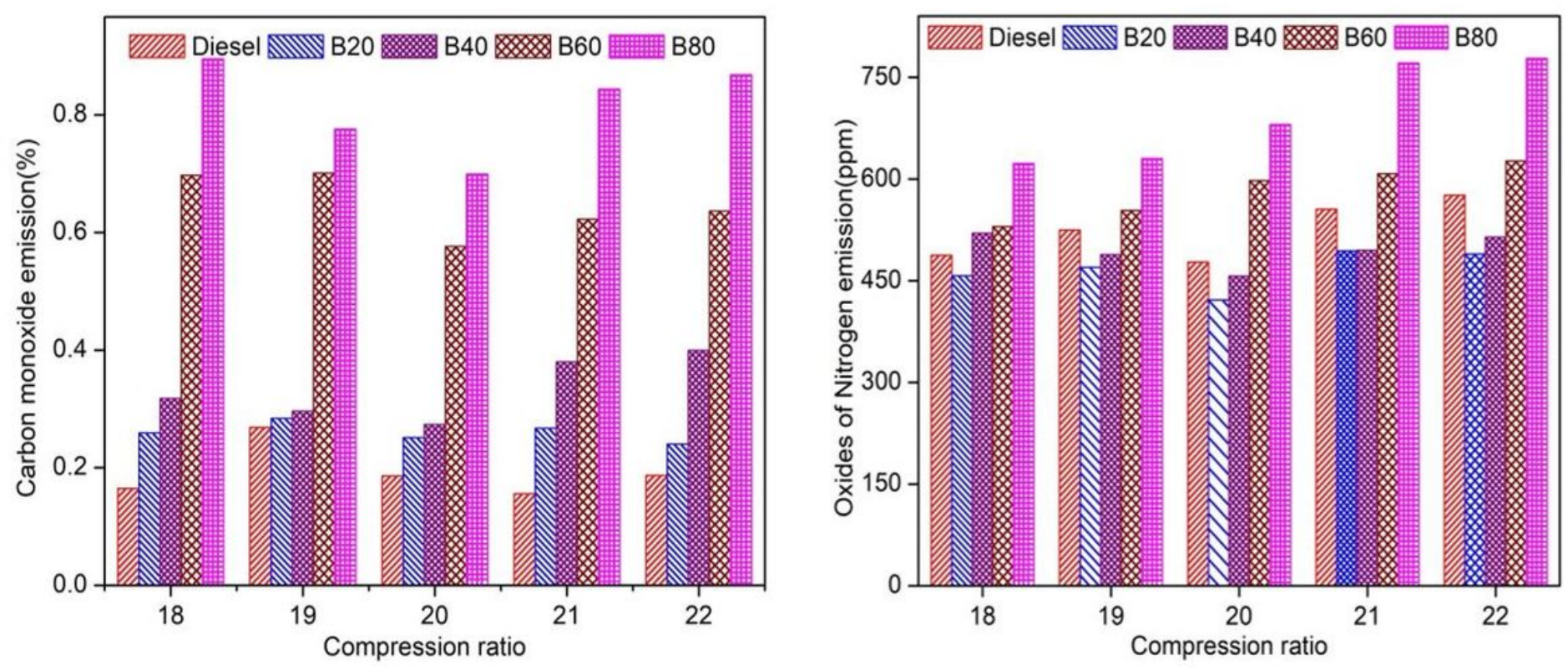
Figure 5

$\mathrm{CO}$ and NOx emission of blends under varying CR
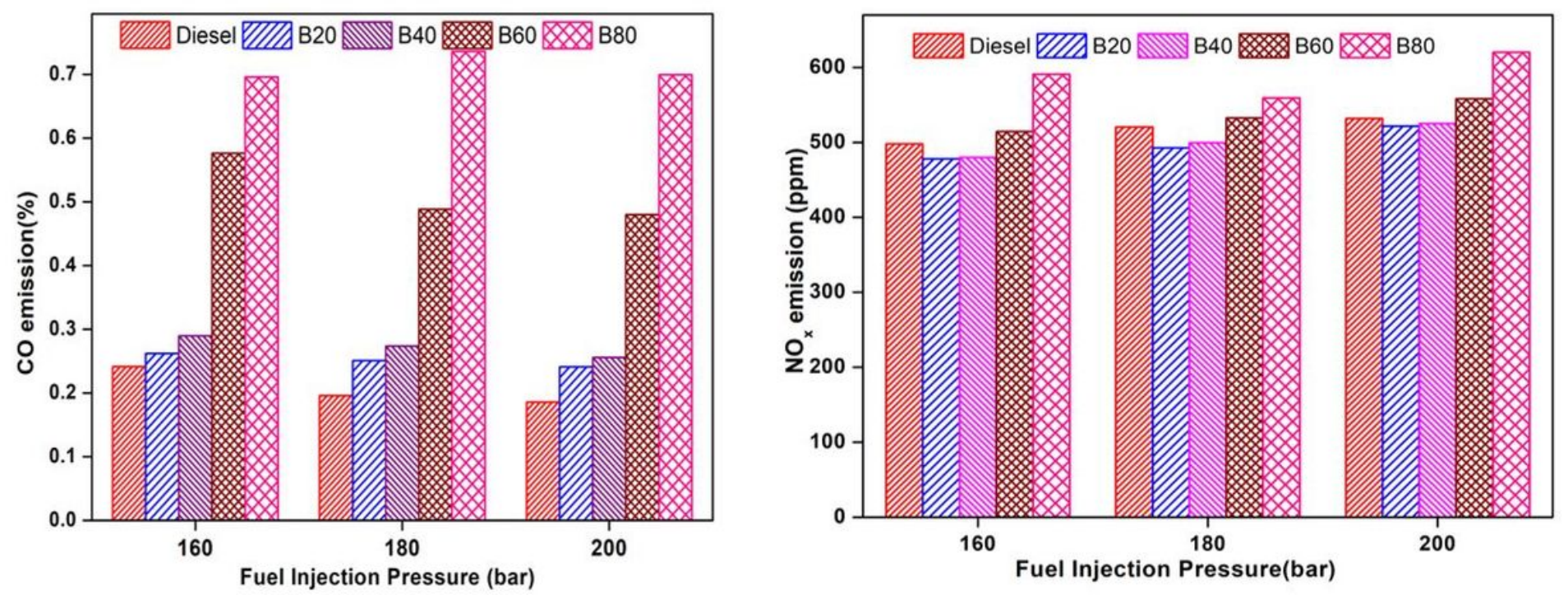

Figure 6

$\mathrm{CO}$ and NOx emission of blends under varying FIP
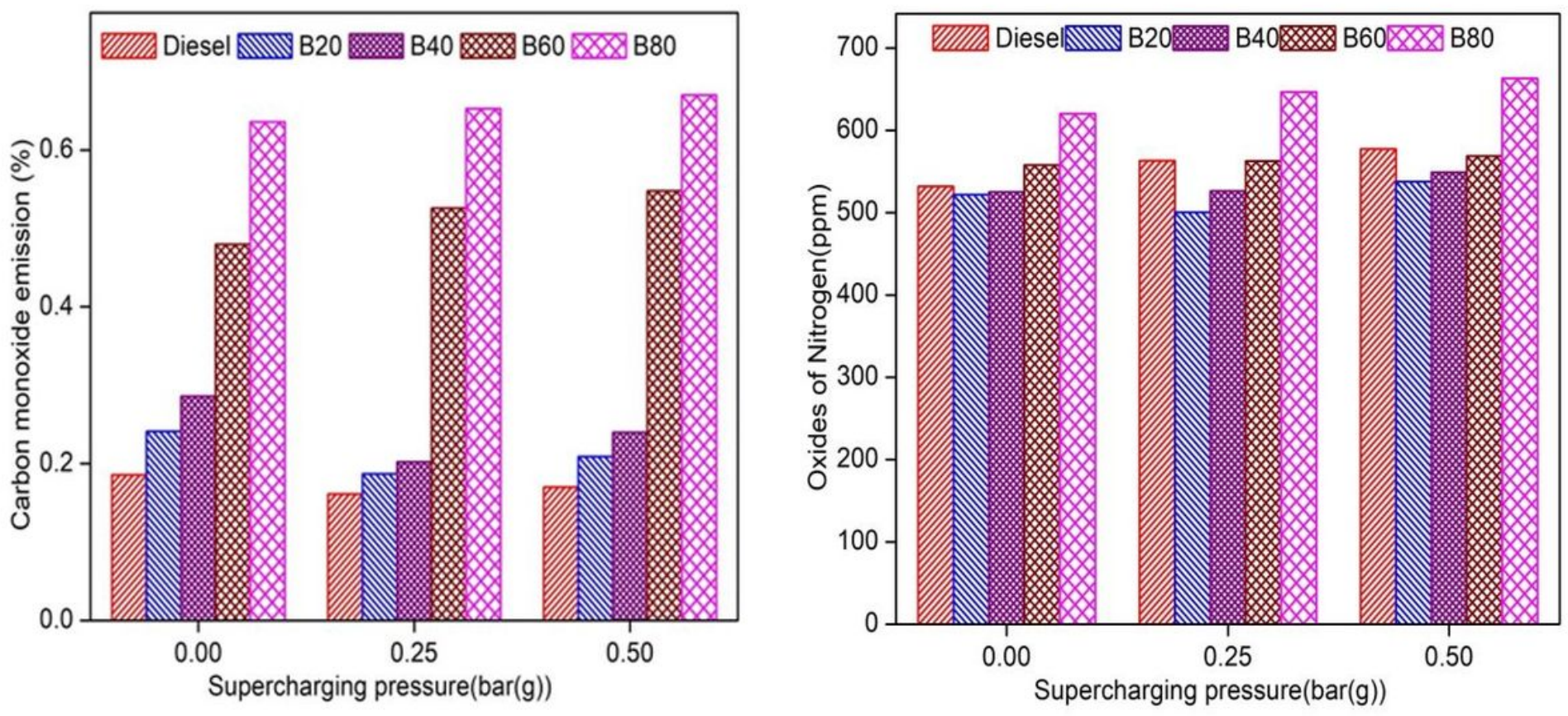

Figure 7

$\mathrm{CO}$ and NOx emission of blends under varying SC 

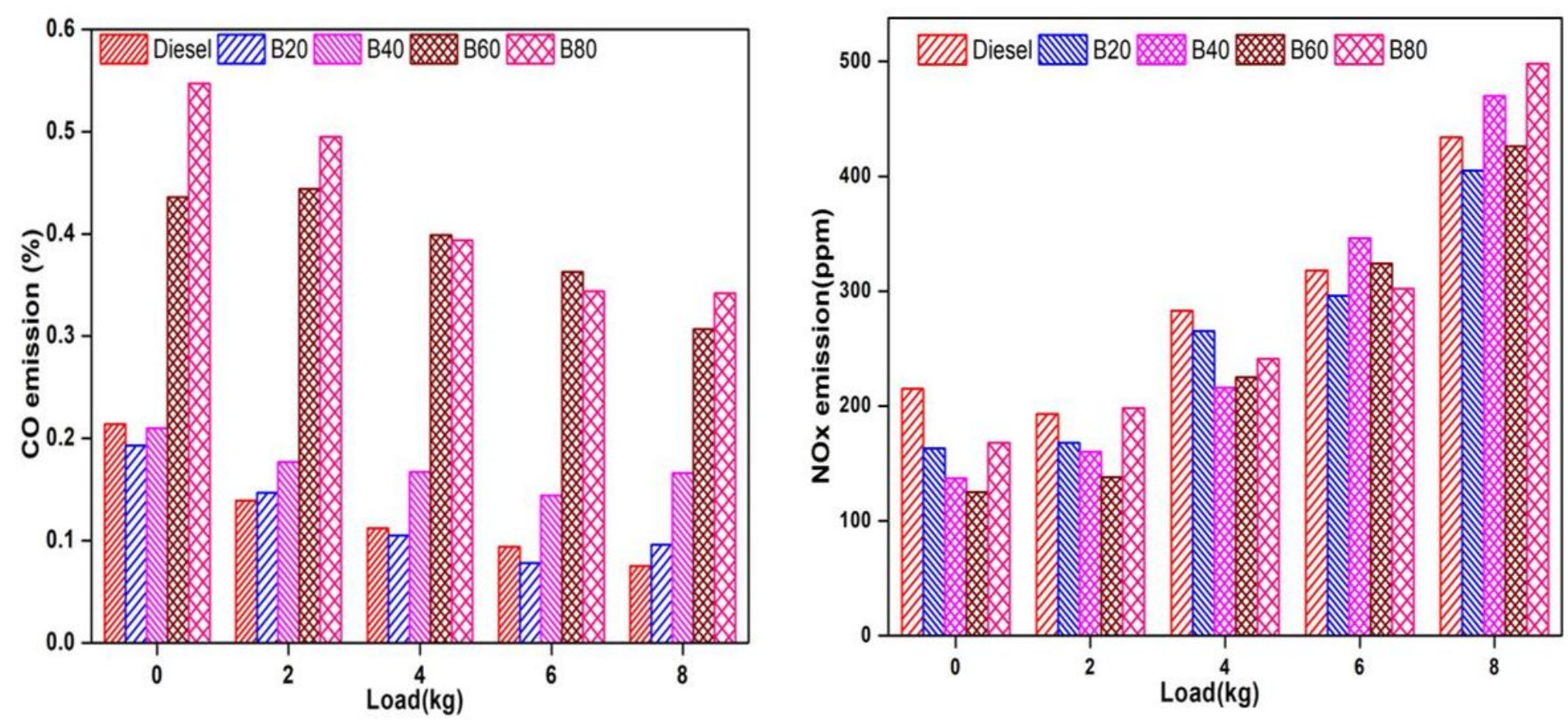

Figure 8

$\mathrm{CO}$ and $\mathrm{NO}_{\mathrm{x}}$ emission of blends under varying Load
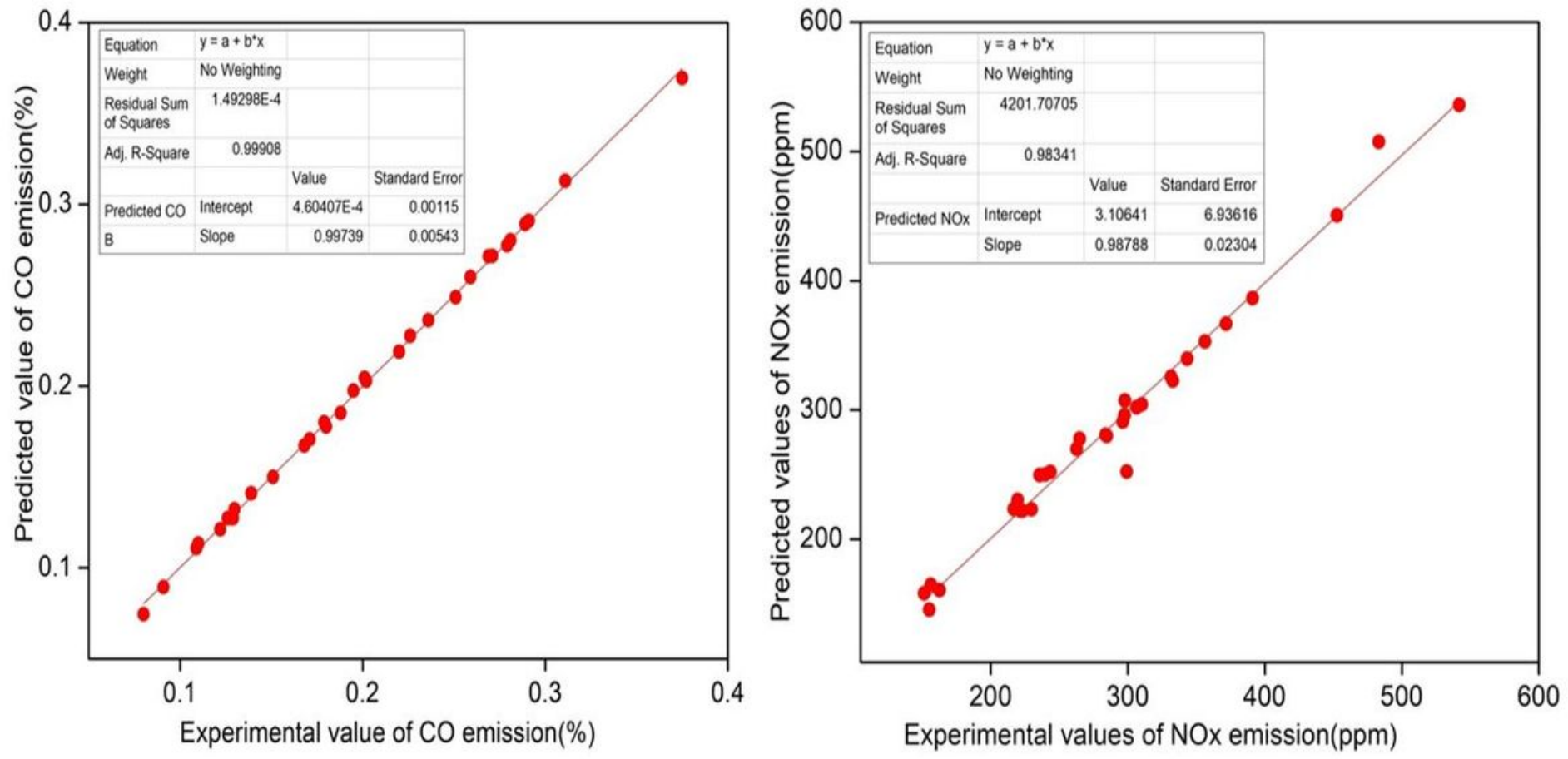

Figure 9

Predicted CO \& NOx values with experimental results 